\title{
Occurrence and Recurrence of Hepatocellular Carcinoma Were Not Rare Events during Phlebotomy in Older Hepatitis C Virus-Infected Patients
}

\author{
Tatsuo Kanda Shingo Nakamoto Shin Yasui Masato Nakamura \\ Tatsuo Miyamura Shuang $\mathrm{Wu}$ Xia Jiang Makoto Arai Fumio Imazeki \\ Osamu Yokosuka
}

Department of Gastroenterology and Nephrology, Graduate School of Medicine, Chiba University, Chiba, Japan

\section{Key Words}

Adverse events · Hepatitis C virus - Hepatocellular carcinoma · Nonalcoholic fatty liver disease Phlebotomy

\begin{abstract}
The use of phlebotomy is relatively common for 'difficult-to-treat by antiviral therapies' hepatitis $\mathrm{C}$ virus (HCV)-infected patients and for certain patients having chronic liver diseases with an iron overload of the liver. In the present study, we retrospectively analyzed patients treated with phlebotomy and their adverse events. We observed the occurrence and recurrence of hepatocellular carcinoma, and the appearance of ascites in some patients infected with HCV as well as the reduction of serum ferritin and alanine aminotransferase levels. Severe adverse events necessitating a cessation of phlebotomy occurred independently of $\alpha$-fetoprotein $(\geq 10 \mathrm{ng} / \mathrm{ml}$ ) in patients infected with HCV according to multivariate logistic regression analysis. These findings may serve as a basis for phlebotomy especially in older patients with chronic hepatitis $C$.

(c) 2014 S. Karger AG, Basel
\end{abstract}




\section{Introduction}

In patients with chronic liver diseases such as chronic hepatitis C, hereditary hemochromatosis and nonalcoholic steatohepatitis, iron depletion by phlebotomy improves serum alanine aminotransferase (ALT) levels [1-4]. Nonresponder patients still exist, although antiviral treatments for hepatitis $\mathrm{C}$ virus (HCV)-infected patients have been developed, and these new therapies are currently available [5-8]. Several treatments have proven to reduce serum ALT levels, such as phlebotomy, ursodeoxycholic acid and Stronger Neo-Minophagen C, a glycyrrhizin [9]. These treatments might be effective in HCV-infected patients without achieving a sustained virological response [9].

Iron overload is one of the abnormal laboratory values in patients with chronic hepatitis $C$, showing elevation of the serum ferritin level [10]. About $30-40 \%$ of patients with chronic HCV infection have elevated serum iron, transferrin saturation and heightened ferritin levels [11]. Hepcidin is a 25-amino-acid peptide that is synthesized in the liver and modulates iron homeostasis in the body $[11,12]$. Hepcidin is a type II acute phase protein whose upregulation systemically suspends iron absorption from intestinal enterocytes and iron recycling from macrophages [11]. Patients infected with HCV have reduced serum hepcidin levels, which are correlated with worse necroinflammation and fibrosis of the liver $[12,13]$. Thus, hepcidin may play a role in the pathogenesis of iron overload in patients with chronic hepatitis C [14].

It was reported that serum ferritin is an independent predictor of histological severity and advanced fibrosis in patients with nonalcoholic fatty liver disease (NAFLD) [15]. Patients with alcoholic liver disease frequently exhibit increased body iron stores, as reflected by higher serum ferritin levels and hepatic iron concentration [16]. It is unknown whether iron depletion by phlebotomy is a useful therapy, although phlebotomy improves serum ferritin levels $[17,18]$.

In Japan, the average age of patients infected with HCV is becoming increasingly higher. Many HCV-infected older people did not respond to peginterferon plus ribavirin therapies or could not undergo these treatments either with or without direct-acting antivirals against HCV due to certain medical conditions $[19,20]$. Chronic hepatitis C patients with advanced liver fibrosis are at risk for hepatocellular carcinoma (HCC). Older age as well as advanced liver fibrosis is one of the risk factors associated with HCC [20,21]. We have recently had an increased number of opportunities to perform phlebotomy in patients with HCV or NAFLD. In the present study, we retrospectively analyzed patients undergoing phlebotomy and their adverse events. Occurrence and recurrence of HCC, and the appearance of ascites in some of the HCV-infected patients as well as the reduction of serum ferritin and ALT levels were observed. We also found that severe adverse events, requiring a cessation of phlebotomy, occurred independently of $\alpha$-fetoprotein (AFP, $\geq 10 \mathrm{ng} / \mathrm{ml}$ ) in patients infected with HCV according to multivariate logistic regression analysis. These findings might serve as a basis for phlebotomy especially in older patients infected with HCV.

\section{Patients and Methods}

\section{Patients}

We retrospectively analyzed 26 patients with chronic liver disease who had undergone phlebotomy for at least 6 months at the Chiba University Hospital. Patients were eligible if they met the following inclusion criteria: (1) age $\geq 20$ years, (2) no pregnancy, (3) no severe heart disease, (4) no abnormal hemoglobinemia, (5) no chronic renal disease, (6) no hepatic 
Kanda et al.: Occurrence and Recurrence of Hepatocellular Carcinoma Were Not Rare Events during Phlebotomy in Older Hepatitis C Virus-Infected Patients

failure, and (7) no current intravenous drug abuse. This analysis was approved by the ethics committee of the Chiba University School of Medicine, and informed consent was obtained from all patients. In this study, phlebotomy of 200-400 ml was performed every 1 or 2 months at the outpatient clinic of the Chiba University Hospital. Clinical and laboratory assessments were also performed each time. Abdominal ultrasound was performed at least once every 6 months. Adverse events were noted by verbal inquiry, physical examinations and laboratory tests. HCV RNA was measured by the COBAS TaqMan HCV test (Roche Diagnostics, Tokyo, Japan), with levels ranging from 1.2 to $7.8 \mathrm{log} \mathrm{IU} / \mathrm{ml}$ [20]. Serum aspartate aminotransferase (AST), ALT, ferritin, hemoglobin and other laboratory tests were carried out by standard methods.

Definition of Severe Adverse Events

Severe adverse events were defined as events requiring a cessation of phlebotomy.

Diagnosis of Hepatic Cirrhosis

Patients were diagnosed as having cirrhosis mainly by ultrasound examination. Six patients infected with HCV and 2 patients without HCV were diagnosed with cirrhosis using mainly liver biopsy.

\section{Diagnosis of HCC}

Patients were subsequently followed up using an HCC surveillance program based on biochemical and US evaluation every 3-6 months as previously described [20]. An intrahepatic nodule was considered to be HCC on computed tomography or magnetic resonance imaging when both the hypervascular nodule in the arterial phase and the hypovascular nodule in the late phase were shown [20].

\section{Statistical Analysis}

Data were expressed as mean \pm SD. Differences were evaluated by Student's $t$ test or $\chi^{2}$. $\mathrm{p}<0.05$ was considered statistically significant. Variables with $\mathrm{p}<0.05$ at univariate analysis were retained for multiple logistic regression analysis. Statistical analysis was performed using the Excelstatistics program for Windows, version 7 (SSRI, Tokyo, Japan).

\section{Results}

\section{Patient Characteristics}

The characteristics of all 26 patients are shown in table 1. Mean age was 63.9 years. Of a total of 21 patients infected with HCV, 20 were monoinfected with HCV and 1 was coinfected with hepatitis B virus and HCV. In the HCV group, 15 and 6 were infected with HCV genotype 1 and genotype 2, respectively; 15 of the $21 \mathrm{HCV}$-positive patients had received interferon treatment, and 5 of the 21 patients had received treatment for HCC. Of all 26 patients, 13 patients were diagnosed with cirrhosis. Of the 5 patients with NAFLD, 2 each showed fibrosis staging of F2 and F4, respectively. These 4 patients and 1 other patient had nonalcoholic steatohepatitis and simple steatosis, respectively. The body mass index and the albumin level of patients with NAFLD tended to be higher than those of patients infected with HCV. 


\section{Effects of Phlebotomy on Laboratory Data of All 26 Patients}

In all 26 patients, AST, ALT, hemoglobin and ferritin were significantly reduced by phlebotomy (fig. 1). Among the other parameters, $\gamma$-glutamyltransferase and AFP levels tended to be reduced by phlebotomy (from $88.8 \pm 95.7$ to $56.1 \pm 56.8, p=0.140$, and from $8.6 \pm 6.9$ to $6.5 \pm 4.0, p=0.185$, respectively). These results indicated that phlebotomy was effective in providing an improvement in AST and ALT levels as has been shown in previous reports [14].

Effects of Phlebotomy on Laboratory Data in a Total of 21 Patients Infected with HCV

Next, we compared the data of patients infected with HCV before and after phlebotomy. In the $21 \mathrm{HCV}$-infected individuals, ALT, hemoglobin and ferritin levels were significantly reduced by phlebotomy, although the HCV RNA level did not change (table 2). Among the other parameters, AST and AFP levels tended to be reduced by phlebotomy. Although the study population was very small (data not shown), among the 5 patients with NAFLD, only AST and ferritin levels, respectively, tended to be reduced before and after phlebotomy (from $56.2 \pm 24.8$ to $36.2 \pm 15.2, \mathrm{p}=0.162$, and from $248 \pm 219$ to $64.3 \pm 52.4, \mathrm{p}=0.105$ ).

\section{Severe Adverse Events during Phlebotomy}

We observed severe adverse events in 9 patients. Of interest, these 9 patients were all infected with HCV (table 3). In 6 of these 9 patients, the background liver was cirrhotic. One and 3 had occurrence and recurrence of HCC, respectively, and phlebotomy in the other 5 patients was stopped due to angina pectoris in 1, ascites in 1, pleural tuberculosis in 1 , nausea in 1 , and dizziness in 1 . Univariate analysis showed that lower albumin contributed to the occurrence of severe adverse events (table 4). Factors associated with severe adverse events by univariate analysis were again analyzed by multivariate logistic regression analysis. Severe adverse events occurred independently of AFP $(\geq 10 \mathrm{ng} / \mathrm{ml})$ in patients infected with HCV (table 5).

\section{Discussion}

The observation that phlebotomy improves ALT levels has now been confirmed in many studies [1-4], even though iron reduction does not improve the rate of sustained response among previous nonresponders [22]. The present study revealed the possibility that even during phlebotomy, severe adverse events including the occurrence or recurrence of HCC could occur in patients infected with HCV even if their ALT and ferritin levels were improved. Among the patients with severe adverse events in this study, all except 1 were more than 50 years of age (table 3 ).

Kato et al. [23] also performed phlebotomy with low-iron diet therapy in 35 HCVinfected patients, with a mean age of 61 years, and they observed HCC occurrence in 4/35 (11.4\%) during a 6-year period. They found that the average serum ferritin level independently affected the hepatocarcinogenesis rate and the relative risk of HCC in the patients treated with iron depletion therapy. Iron overload is one of the risk factors for the development of HCC in patients infected with chronic HCV infection [24]. Although the study population was small, the present study also showed that chronic phlebotomy treatment is not always useful for the prevention of HCC and that further studies are needed. We cannot exclude the possibility that most of the current study patients infected with HCV might have been patients 'difficult-to-treat' by antiviral therapies such as peginterferon plus ribavirin 
[5]. Of course, among these patients, elderly patients and/or patients with advanced liver fibrosis might be susceptible to HCC [20,21, 25].

In Japan, patients infected with HCV are getting increasingly older, and they are older than those in other countries [19, 26]. Matsuo et al. [26] reported that HCC developed more frequently in blood donors in whom chronic hepatitis had been diagnosed at age $\geq 60$ years than $\leq 59$ years. In the era of direct-acting antivirals against $\operatorname{HCV}[27,28]$, our current study strongly suggests that HCV-infected patients $>50$ years might be treated with antivirals as soon as possible. If certain treatments such as phlebotomy were temporarily selected, attention should be paid to the potential occurrence or recurrence of HCC or the occurrence of other complications during these treatments. In the present study, in 4 (30.7\%) patients of 13 cirrhotic patients, phlebotomy was stopped due to the occurrence or recurrence of HCC.

In conclusion, the occurrence or recurrence of HCC or hepatic failure with ascites was observed in certain patients infected with HCV in addition to the reduction of serum ferritin and ALT levels during phlebotomy. Severe adverse events, which required phlebotomy to be stopped, occurred independently of AFP $(\geq 10 \mathrm{ng} / \mathrm{ml})$ in patients infected with HCV according to multivariate logistic regression analysis. The findings of this study will provide a guideline as a basis for phlebotomy treatments, especially for older patients with chronic hepatitis C. If possible, older patients infected with HCV should also be treated with antiviral agents.

\section{Acknowledgments}

This work was supported by Research Grants for Scientific Research from the Ministry of Education, Culture, Sports, Science, and Technology, Japan (T.K., S.N., S.W. and O.Y.).

\section{Disclosure Statement}

Tatsuo Kanda reports receiving lecture fees from Chugai Pharmaceutical, MSD, Tanabe-Mitsubishi, Ajinomoto, Bristol-Myers Squibb, Daiichi-Sankyo, Janssen Pharmaceutical, and GlaxoSmithKline. Osamu Yokosuka reports receiving grant support from Chugai Pharmaceutical, Bayer, MSD, Daiichi-Sankyo, Tanabe-Mitsubishi, and Bristol-Myers Squibb.

\section{References}

1 Hayashi H, Takikawa T, Nishimura N, Yano M, Isomura T, Sakamoto N: Improvement of serum aminotransferase levels after phlebotomy in patients with chronic active hepatitis $\mathrm{C}$ and excess hepatic iron. Am J Gastroenterol 1994;89:986-988.

2 Bacon BR: Available options for treatment of interferon nonresponders. Am J Med 1999;107(6B):67S-70S.

-3 Kato J, Miyanishi K, Kobune M, Nakamura T, Takada K, Takimoto R, Kawano Y, Takahashi S, Takahashi M, Sato Y, Takayama T, Niitsu Y: Long-term phlebotomy with low-iron diet therapy lowers risk of development of hepatocellular carcinoma from chronic hepatitis C. J Gastroenterol 2007;42:830-836.

4 Beaton MD, Chakrabarti S, Levstik M, Speechley M, Marotta P, Adams P: Phase II clinical trial of phlebotomy for non-alcoholic fatty liver disease. Aliment Pharmacol Ther 2013;37:720-729.

5 Kanda T, Imazeki F, Yokosuka 0: New antiviral therapies for chronic hepatitis C. Hepatol Int 2010;4:548561.

6 McHutchison JG, Manns MP, Muir AJ, Terrault NA, Jacobson IM, Afdhal NH, Heathcote EJ, Zeuzem S, Reesink HW, Garg J, Bsharat M, George S, Kauffman RS, Adda N, Di Bisceglie AM; PROVE3 Study Team: Telaprevir for previously treated chronic HCV infection. N Engl J Med 2010;362:1292-1303. 
7 Bacon BR, Gordon SC, Lawitz E, Marcellin P, Vierling JM, Zeuzem S, Poordad F, Goodman ZD, Sings HL, Boparai N, Burroughs M, Brass CA, Albrecht JK, Esteban R; HCV RESPOND-2 Investigators: Boceprevir for previously treated chronic HCV genotype 1 infection. N Engl J Med 2011;364:1207-1217.

-8 Izumi N, Hayashi N, Kumada H, Okanoue T, Tsubouchi H, Yatsuhashi H, Kato M, Ki R, Komada Y, Seto C, Goto S: Once-daily simeprevir with peginterferon and ribavirin for treatment-experienced HCV genotype 1infected patients in Japan: the CONCERTO-2 and CONCERTO-3 studies. J Gastroenterol 2014, Epub ahead of print.

-9 Omata M, Kanda T, Yu ML, Yokosuka O, Lim SG, Jafri W, Tateishi R, Hamid SS, Chuang WL, Chutaputti A, Wei L, Sollano J, Sarin SK, Kao JH, McCaughan GW: APASL consensus statements and management algorithms for hepatitis C virus infection. Hepatol Int 2012;6:409-435.

10 Carreño V: Review article: management of chronic hepatitis C in patients with contraindications to anti-viral therapy. Aliment Pharmacol Ther 2014;39:148-162.

11 Georgopoulou U, Dimitriadis A, Foka P, Karamichali E, Mamalaki A: Hepcidin and the iron enigma in HCV infection. Virulence 2014, Epub ahead of print.

-12 Tsochatzis E, Papatheodoridis GV, Koliaraki V, Hadziyannis E, Kafiri G, Manesis EK, Mamalaki A, Archimandritis AJ: Serum hepcidin levels are related to the severity of liver histological lesions in chronic hepatitis C. J Viral Hepat 2010;17:800-806.

13 Fujita N, Sugimoto R, Motonishi S, Tomosugi N, Tanaka H, Takeo M, Iwasa M, Kobayashi Y, Hayashi H, Kaito M, Takei Y: Patients with chronic hepatitis $\mathrm{C}$ achieving a sustained virological response to peginterferon and ribavirin therapy recover from impaired hepcidin secretion. J Hepatol $2008 ; 49: 702-710$.

14 Fujita N, Sugimoto R, Takeo M, Urawa N, Mifuji R, Tanaka H, Kobayashi Y, Iwasa M, Watanabe S, Adachi Y, Kaito M: Hepcidin expression in the liver: relatively low level in patients with chronic hepatitis C. Mol Med 2007;13:97-104.

15 Bambha K, Belt P, Abraham M, Wilson LA, Pabst M, Ferrell L, Unalp-Arida A, Bass N; Nonalcoholic Steatohepatitis Clinical Research Network Research Group: Ethnicity and nonalcoholic fatty liver disease. Hepatology 2012;55:769-780.

16 Harrison-Findik DD: Role of alcohol in the regulation of iron metabolism. World J Gastroenterol 2007;13:4925-4930.

-17 Facchini FS, Hua NW, Stoohs RA: Effect of iron depletion in carbohydrate-intolerant patients with clinical evidence of nonalcoholic fatty liver disease. Gastroenterology 2002;122:931-939.

18 Sumida Y, Kanemasa K, Fukumoto K, Yoshida N, Sakai K, Nakashima T, Okanoue T: Effect of iron reduction by phlebotomy in Japanese patients with nonalcoholic steatohepatitis: a pilot study. Hepatol Res 2006;36:315-321.

19 Kanda T, Nakamoto S, Wu S, Yokosuka O: Role of IL28B genotype in older hepatitis C virus-infected patients. World J Immunol 2013;3:54-61.

20 Kanda T, Imazeki F, Mikami S, Kato K, Shimada N, Yonemitsu Y, Miyauchi T, Arai M, Fujiwara K, Tsubota A, Takada N, Nishino T, Takashi M, Sugiura N, Kimura M, Fukai K, Yokosuka O: Occurrence of hepatocellular carcinoma was not a rare event during and immediately after antiviral treatment in Japanese HCV-positive patients. Oncology 2011;80:366-372.

21 Yu ML, Lin SM, Chuang WL, Dai CY, Wang JH, Lu SN, Sheen IS, Chang WY, Lee CM, Liaw YF: A sustained virological response to interferon or interferon/ribavirin reduces hepatocellular carcinoma and improves survival in chronic hepatitis C: a nationwide, multicentre study in Taiwan. Antivir Ther 2006;11:985-994. Di Bisceglie AM, Bonkovsky HL, Chopra S, Flamm S, Reddy RK, Grace N, Killenberg P, Hunt C, Tamburro C, Tavill AS, Ferguson R, Krawitt E, Banner B, Bacon BR: Iron reduction as an adjuvant to interferon therapy in patients with chronic hepatitis $\mathrm{C}$ who have previously not responded to interferon: a multicenter, prospective, randomized, controlled trial. Hepatology 2000;32:135-138.

23 Kato J, Miyanishi K, Kobune M, Nakamura T, Takada K, Takimoto R, Kawano Y, Takahashi S, Takahashi M, Sato Y, Takayama T, Niitsu Y: Long-term phlebotomy with low-iron diet therapy lowers risk of development of hepatocellular carcinoma from chronic hepatitis C. J Gastroenterol 2007;42:830-836.

24 Heathcote EJ: Prevention of hepatitis C virus-related hepatocellular carcinoma. Gastroenterology 2004;127(5 suppl 1):S294-S302.

25 Kanda T, Yokosuka 0, Omata M: Antiviral therapy for 'difficult-to-treat' hepatitis C virus-infected patients. Chin Med J (Engl) 2013;126:4568-4574.

-26 Matsuo J, Mizui M, Okita H, Katayama K, Aimitsu S, Sakata T, Obayashi M, Nakanishi T, Chayama K, Miyakawa Y, Yoshizawa H, Tanaka J; Hiroshima Hepatitis Study Group: Follow up of the 987 blood donors found with hepatitis C virus infection over 9-18 years. Hepatol Res 2012;42:637-647.

27 Sulkowski MS, Gardiner DF, Rodriguez-Torres M, Reddy KR, Hassanein T, Jacobson I, Lawitz E, Lok AS, Hinestrosa F, Thuluvath PJ, Schwartz H, Nelson DR, Everson GT, Eley T, Wind-Rotolo M, Huang SP, Gao M, Hernandez D, McPhee F, Sherman D, Hindes R, Symonds W, Pasquinelli C, Grasela DM; AI444040 Study Group: Daclatasvir plus sofosbuvir for previously treated or untreated chronic HCV infection. N Engl J Med 2014;370:211-221.

28 Kowdley KV, Lawitz E, Poordad F, Cohen DE, Nelson DR, Zeuzem S, Everson GT, Kwo P, Foster GR, Sulkowski MS, Xie W, Pilot-Matias T, Liossis G, Larsen L, Khatri A, Podsadecki T, Bernstein B: Phase $2 \mathrm{~b}$ trial of interferon-free therapy for hepatitis C virus genotype 1. N Engl J Med 2014;370:222-232. 
Table 1. Baseline characteristics of total patients in this study

\begin{tabular}{lcccl}
\hline Factors & $\begin{array}{c}\text { Total patients } \\
(\mathrm{n}=26)\end{array}$ & $\begin{array}{c}\text { HCV group } \\
(\mathrm{n}=21)\end{array}$ & $\begin{array}{c}\text { NAFLD group } \\
(\mathrm{n}=5)\end{array}$ & $\begin{array}{l}\text { p values }{ }^{1} \\
\text { (HCV vs. NAFLD) }\end{array}$ \\
\hline Age, years & $63.9 \pm 9.3$ & $64.6 \pm 8.7$ & $61 \pm 12.4$ & n.s. \\
Males/females, $\mathrm{n}$ & $14 / 12$ & $13 / 8$ & $1 / 4$ & n.s. \\
Body mass index & $24.4 \pm 3.9$ & $23.6 \pm 3.4$ & $26.9 \pm 4.5$ & 0.078 \\
Cirrhosis $(+/-)$ & $13 / 13$ & $11 / 10$ & $2 / 3$ & n.s. \\
Past history of HCC $(+/-)$ & $5 / 21$ & $5 / 16$ & $0 / 5$ & n.s. \\
AST, IU/l & $62.7 \pm 31.0$ & $64.2 \pm 32.6$ & $56.2 \pm 24.8$ & n.s. \\
ALT, IU/l & $77.3 \pm 51.8$ & $75.3 \pm 47.5$ & $86 \pm 73.4$ & n.s. \\
$\gamma$-GTP, IU/l & $88.8 \pm 95.7$ & $94.4 \pm 104$ & $66.4 \pm 47.0$ & n.s. \\
Total bilirubin, mg/dl & $1.0 \pm 0.53$ & $0.98 \pm 0.47$ & $1.2 \pm 0.78$ & n.s. \\
Albumin, g/dl & $4.2 \pm 0.39$ & $4.2 \pm 0.41$ & $4.5 \pm 0.13$ & 0.123 \\
Hemoglobin, g/dl & $13.8 \pm 1.5$ & $13.7 \pm 1.5$ & $14.4 \pm 1.2$ & n.s. \\
Platelets, $\times 104 / \mu l$ & $13.4 \pm 4.6$ & $12.2 \pm 4.0$ & $18.3 \pm 3.8$ & 0.00500 \\
AFP, ng/ml & $8.6 \pm 6.9$ & $9.7 \pm 7.3$ & $4.3 \pm 1.6$ & 0.118 \\
Ferritin, ng/ml & $213 \pm 176$ & $205 \pm 169$ & $248 \pm 219$ & n.s. \\
Total volume of phlebotomy & & & & \\
$\quad(<2.4 / \geq 2.4$ liters) & $17 / 9$ & $12 / 9$ & $5 / 0$ & 0.197 \\
\hline
\end{tabular}

Data are expressed as mean \pm SD. $\gamma$-GTP $=\gamma$-Glutamyltransferase; $n . s .=$ not statistically significant. ${ }^{1} \mathrm{p}$ values between the HCV group and the NAFLD group are indicated by Student's t test or $\chi^{2}$ test.

Table 2. Changes in laboratory data before and after phlebotomy in a total of $21 \mathrm{HCV}$-positive patients

\begin{tabular}{lccl}
\hline Factors & $\begin{array}{l}\text { Before phlebotomy } \\
(\mathrm{n}=21)\end{array}$ & $\begin{array}{l}\text { After phlebotomy } \\
(\mathrm{n}=21)\end{array}$ & p values $^{1}$ \\
\hline HCV RNA, log IU/ml & $5.89 \pm 1.58$ & $5.87 \pm 1.65$ & \\
AST, IU/l & $64.2 \pm 32.6$ & $49.5 \pm 25.1$ & n.s. \\
ALT, IU/l & $75.3 \pm 47.5$ & $48.3 \pm 28.2$ & 0.109 \\
$\gamma$-GTP, IU/l & $94.4 \pm 104$ & $60.9 \pm 62.3$ & 0.0307 \\
Total bilirubin, mg/dl & $0.98 \pm 0.47$ & $0.83 \pm 0.47$ & n.s. \\
Albumin, g/dl & $4.2 \pm 0.41$ & $4.0 \pm 0.48$ & n.s. \\
Hemoglobin, g/dl & $13.7 \pm 1.5$ & $12.7 \pm 1.4$ & n.s. \\
Platelets, $\times 10^{4} / \mu \mathrm{l}$ & $12.2 \pm 4.0$ & $13.0 \pm 4.4$ & 0.0398 \\
AFP, ng/ml & $9.7 \pm 7.3$ & $7.1 \pm 4.2$ & n.s. \\
Ferritin, $\mathrm{ng} / \mathrm{ml}$ & $205 \pm 169$ & $38.9 \pm 32.5$ & 0.164 \\
\hline
\end{tabular}

Data are expressed as mean \pm SD. $\gamma$-GTP $=\gamma$-Glutamyltransferase; $n . s .=$ not statistically significant. ${ }^{1} \mathrm{p}$ values between before and after phlebotomy are indicated by Student's t test or $\chi^{2}$ test. 
Table 3. Nine patients infected with HCV no longer received phlebotomy due to severe adverse events

\begin{tabular}{|c|c|c|c|c|c|c|}
\hline $\begin{array}{l}\text { Age, } \\
\text { years }\end{array}$ & $\begin{array}{l}\text { Gender } \\
\text { s }\end{array}$ & Background & $\begin{array}{l}\text { Phlebotomy (total } \\
\text { volume/duration), } \\
\text { l/months }\end{array}$ & $\begin{array}{l}\text { Severe } \\
\text { adverse events }\end{array}$ & $\begin{array}{l}\text { Hemoglobin } \\
\text { (before } \\
\text { phlebotomy), } \\
\text { g/dl }\end{array}$ & $\begin{array}{l}\text { Hemoglobin } \\
\text { (after } \\
\text { phlebotomy), } \\
\text { g/dl }\end{array}$ \\
\hline 69 & Male & Cirrhosis & $<2.4 / 12$ & Angina pectoris & 16 & 14 \\
\hline 79 & Male & Cirrhosis & $<2.4 / 6$ & $\mathrm{HCC}$ & 13.8 & 12.4 \\
\hline 62 & Male & Cirrhosis, post-HCC therapy & $<2.4 / 10$ & HCC recurrence & 10.6 & 12.5 \\
\hline 54 & Male & Cirrhosis, post-HCC therapy & $\geq 2.4 / 26$ & HCC recurrence & 12.3 & 12.5 \\
\hline 65 & Male & Cirrhosis, post-HCC therapy & $<2.4 / 6$ & HCC recurrence & 13.7 & 12.1 \\
\hline 67 & Female & Chronic hepatitis & $<2.4 / 6$ & Nausea & 14.2 & 12 \\
\hline 73 & Male & Chronic hepatitis, type $\mathrm{B}+\mathrm{C}$ & $\geq 2.4 / 93$ & Pleural tuberculosis & 13.3 & 13 \\
\hline 48 & Female & Cirrhosis & $<2.4 / 16$ & Ascites & 13 & 11.1 \\
\hline 79 & Male & Chronic hepatitis & $\geq 2.4 / 24$ & Dizziness & 15.5 & 11.1 \\
\hline
\end{tabular}

Table 4. Comparison of baseline characteristics of HCV-infected patients with and without severe adverse events by univariate analysis

\begin{tabular}{lccl}
\hline Factors & $\begin{array}{l}\text { With severe adverse events } \\
(\mathrm{n}=9)\end{array}$ & $\begin{array}{c}\text { Without severe adverse } \\
\text { events }(\mathrm{n}=12)\end{array}$ & $\mathrm{p}^{\text {values }}{ }^{1}$ \\
\hline Age, years & $66.2 \pm 10.4$ & $63.4 \pm 7.3$ & n.s. \\
Males/females & $7 / 2$ & $6 / 6$ & n.s. \\
Body mass index & $24.4 \pm 4.7$ & $23.1 \pm 2.6$ & n.s. \\
Cirrhosis $(+/-)$ & $6 / 3$ & $5 / 7$ & n.s. \\
Past history of HCC $(+/-)$ & $3 / 6$ & $2 / 10$ & n.s. \\
AST, IU/l & $74.2 \pm 38.8$ & $56.8 \pm 26.3$ & n.s. \\
ALT, IU/l & $83.6 \pm 57.0$ & $69.0 \pm 40.4$ & n.s. \\
$\gamma$-GTP, IU/l & $140 \pm 137$ & $56.5 \pm 46.2$ & 0.0622 \\
Total bilirubin, mg/dl & $1.0 \pm 0.59$ & $0.94 \pm 0.39$ & n.s. \\
Albumin, g/dl & $3.9 \pm 0.48$ & $4.4 \pm 0.23$ & 0.00499 \\
Hemoglobin, g/dl & $13.6 \pm 1.6$ & $13.8+1.5$ & n.s. \\
Platelets, $\times 10^{4} / \mu \mathrm{l}$ & $11.5 \pm 3.5$ & $12.7 \pm 4.3$ & n.s. \\
AFP, ng/ml & $12.9 \pm 8.8$ & $7.2 \pm 5.0$ & 0.0749 \\
Ferritin, ng/ml & $276 \pm 208$ & $152 \pm 116$ & 0.0973 \\
Total volume of phlebotomy & & & \\
$\quad(<2.4 / \geq 2.4$ liters $)$ & $6 / 3$ & $6 / 6$ & n.s. \\
\hline
\end{tabular}

Data are expressed as mean \pm SD. $\gamma$-GTP $=\gamma$-Glutamyltransferase; n.s. $=$ not statistically significant. ${ }^{1} \mathrm{p}$ values between the HCV group and the NAFLD group are indicated by Student's t test or $\chi^{2}$ test.

Table 5. Factors associated with severe adverse events among patients infected with HCV by multivariate analysis

\begin{tabular}{lllll}
\hline Factor & Category & Odds ratio & $95 \%$ CI & p value \\
\hline AFP & $<10 / \geq 10$ & 10.0 & $1.28-78.1$ & 0.0281 \\
\hline
\end{tabular}




\section{Case Reports in \\ Oncology}

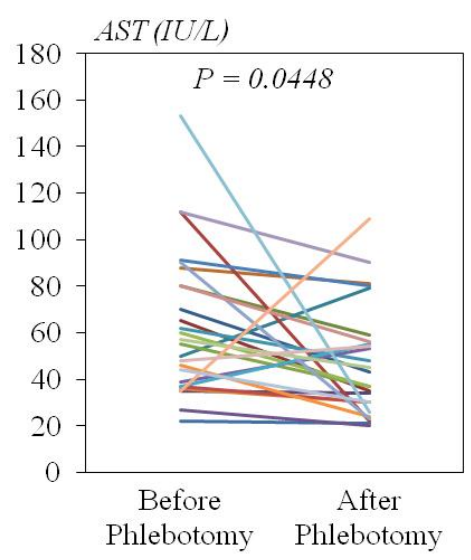

a
Case Rep Oncol 2014;7:288-296 DOI: $10.1159 / 000362869$
(C) 2014 S. Karger AG, Basel www.karger.com/cro

Kanda et al.: Occurrence and Recurrence of Hepatocellular Carcinoma Were Not Rare Events during Phlebotomy in Older Hepatitis C Virus-Infected Patients

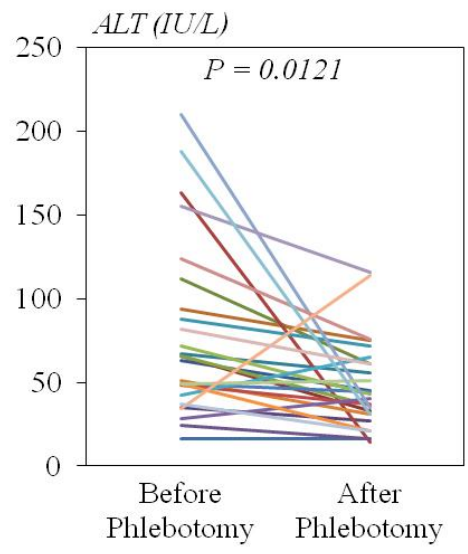

b $\quad 77.3 \pm 51.8 \quad 47.5 \pm 26.9$

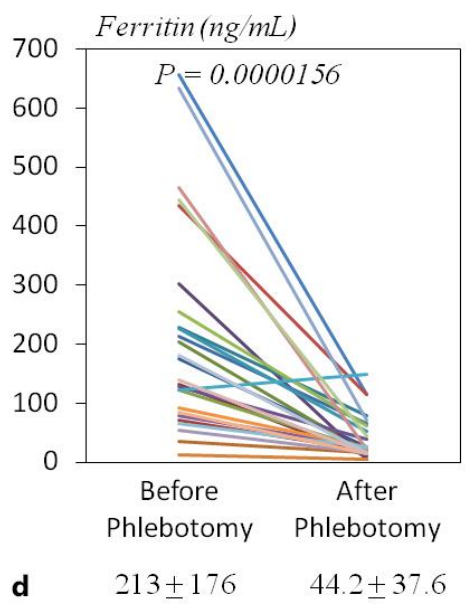

Fig. 1. Changes in AST (a), ALT (b), hemoglobin (c) and ferritin (d) before and after phlebotomy in all the 26 patients. Values below the $\mathrm{x}$-axis represent mean \pm SD. 